\title{
A IMPORTÂNCIA DO MARKETING PARA O AGRONEGÓCIO BRASILEIRO
}

\section{THE IMPORTANCE OF MARKETING FOR BRAZILIAN AGRIBUSINESS}

\author{
Marielena Rangel Soares \\ Graduando, Faculdade Presidente Antônio Carlos, Brasil \\ E-mail: marielenarangelsoares@gmail.com \\ Luiz Felipe da Silva \\ Graduando, Faculdade Presidente Antônio Carlos, Brasil \\ E-mail: luizfellipe067@gmail.com \\ Luis Octavio Oliveira Matos \\ Graduando, Faculdade Presidente Antônio Carlos, Brasil \\ E-mail: loomatos@hotmai.com \\ Paulo Toledo Ribeiro \\ Orientador, Faculdade Presidente Antônio Carlos, Brasil \\ E-mail: pauloagroribeiro@hotmail.com
}

Recebido:21/06/2021 - Aceito: 22/06/2021

\section{Resumo}

O objetivo deste trabalho é analisar sobre o Marketing no Agronegócio, ferramenta forte ao setor na economia do país. O tema justifica-se pelo fato de que o marketing é utilizado em toda a cadeia de produção, proporcionando identidade e valor às marcas e aos produtos promovendo maior atratividade ao setor. Assim sendo, temos a seguinte questão: Qual a importância do marketing para agronegócio brasileiro? Atualmente pode-se ressaltar que além de maximizar o potencial de vendas, o marketing auxilia em toda a gestão do segmento, bem como proporciona grandes inovações que tentam suprir as exigências do mercado. Para responder a essa questão, utilizou-se a pesquisa bibliográfica em artigos, livros e revistas com o intuito de esclarecer o tema pesquisado. Verificou-se que as ações estratégicas de marketing no agronegócio não só contribuem para o desenvolvimento da economia do país favorecendo a possível ampliação do mercado global cada vez mais competitivo. 
Palavras-chave: Agronegócio; Marketing; Economia; Estratégia.

\section{Abstract}

The objective of this paper is to analyze Marketing in Agribusiness, a strong tool for the sector in the country's economy. The theme is justified by the fact that marketing is used throughout the production chain, providing identity and value to brands and products, promoting greater attractiveness to the sector. Therefore, we have the following question: What is the importance of marketing for Brazilian agribusiness? Currently, we can emphasize that, in addition to maximizing sales potential, marketing helps in the entire management of the segment, as well as providing great innovations that try to meet market demands. To answer this question, bibliographical research in articles, books and magazines was used in order to clarify the researched topic. It was found that strategic marketing actions in agribusiness not only contribute to the development of the country's economy, favoring the possible expansion of the increasingly competitive global market.

Keywords: Agribusiness; Marketing; Economy; strategy.

\section{Introdução}

Demorou para o Brasil incorporar e aceitar a ideia de que é um país essencialmente agrícola, como se isso fosse para nós, brasileiros, uma posição vexatória ou que nos condenasse à caipirice. São inegáveis a importância do agronegócio, o quanto se avançou e a potencialidade que tem pela frente. Não são essas conclusões bairristas, mas o que expressou o relatório da Conferência da Organização das Nações Unidas sobre o Comércio e Desenvolvimento (Unctad): em 12 anos, o Brasil tem todas as condições para se tornar o maior produtor agrícola mundial. Ainda segundo o relatório, o país conta com 90 milhões de hectares de terra potencialmente cultiváveis, além de "vantagens naturais imbatíveis" como no setor de carnes e as aberturas que vem encontrando no mercado externo.

Em um mercado tão competitivo e globalizado o agronegócio brasileiro vem contribuindo e muito para a balança comercial do país apresentando saldos bem 
positivos e frequentes. Por conta disso, as empresas estão traçando novas e importantes estratégias mais direcionadas que permitam vencer alguns desafios existentes, como cenários econômicos instáveis e as mudanças de conceitos no consumo, e crescer de forma mais sólida e sustentável. O setor agrícola é destaque pelo seu importante papel no desenvolvimento do país, tanto pela oferta de produtos quanto pela absorção significativa de mão de obra (SANTOS ET AL., 2016).

O setor agrícola é composto por cadeias produtivas que irão atuar em distintos sistemas naturais, e assumirão assim importante papel na economia brasileira através da implementação de modernos projetos de gestão visando aprimorar todo o processo produtivo, maximizando a lucratividade. 0 "agrobusiness", terminologia que vem sendo muito utilizada para denominar os segmentos desta cadeia produtiva agropecuária, inclui as variadas atividades desenvolvidas por fornecedores, equipamentos, serviços, chegando até a comercialização da produção agropecuária, sendo o setor também responsável por inúmeros e grandiosos avanços no setor de produção, alto percentual na geração de renda e empregabilidade, alavancando a economia brasileira, e constituindo-se assim uma peça chave na economia nacional (MAURI et al., 2017).

Os desafios são muitos e são grandes para o desenvolvimento dos agronegócios como até então têm sido os resultados alcançados pelo setor, mas ainda carece da capacidade de fazer bom uso dessa arte e ciência de entender necessidades do mercado consumidor, organizar estratégias para atuar nos mercados e divulgar informações como o claro objetivo de "vender" os bens produzidos. É preciso aprender a fazer estratégia e marketing no agronegócio.

Neste contexto, percebe-se a importância do Marketing no Agronegócio Brasileiro, salientando a seguinte questão: Qual a importância do marketing para o agronegócio brasileiro?

O objetivo geral do estudo é analisar essa questão, essa importância, através da pesquisa bibliográfica em artigos, livros e revistas tendo como objetivos específicos: identificar os desafios do Marketing no Agronegócio Brasileiro e 
compreender como a utilização do Marketing estratégico pode influenciar o agronegócio no Brasil, justificando-se pelo fato de que o marketing traz um grande levantamento de informações que podem propiciar maior vantagem competitiva ao homem do campo, visando atender as exigências dos consumidores e buscando novas tendências de mercado, que contribuirão nesse processo, desde o processo administrativo até a valorização do produto a ser comercializado (MEDINA, 2017).

Justifica-se também pelo fato de que atualmente o marketing é visto, cada vez mais, como um facilitador para que as transações ocorram entre as empresas, cuidando da parte que vai da empresa até o mercado. O Marketing entra para ajudar nessas trocas e em todo o processo de fluxo de informações do sistema auxiliando a empresa a monitorar o ambiente onde opera.

\section{Revisão Bibliográfica}

\subsection{Marketing}

O Marketing cuida da parte que vai da empresa até o mercado. Foi definido como um "processo social e de gestão pelo qual indivíduos e grupos obtêm o que necessitam e querem através da criação, oferta e troca de produtos e valores com outros" (KOTLER, 1997).

McCarthy e Perrault (1997) dizem que, se a maioria das pessoas, inclusive gerentes, fosse forçada a definir marketing, elas diriam que significa "vendas" ou "propaganda". Essa resposta não é totalmente verdadeira, vendas e propaganda fazem parte do que é conhecido como marketing, que inclui diversas outras atividade.

Marketing é usado para entender quais são essas necessidades dos consumidores finais e intermediários (indústrias, distribuidores), através do processo de pesquisa, analisando o comportamento dos consumidores e o mercado, facilitando ver quais segmentos de consumidores podem ser satisfatórios, quais serão alvo de atuação de empresa, que tipo de diferenciação 
pode ser oferecida, como gerar e adaptar produtos, marcas e embalagens, as estratégias corretas de precificação para esses produtos, como colocá-los à disposição dos consumidores através de canais de distribuição e como comunicar melhor através da propaganda, da publicidade e de outras ferramentas.

O marketing tem como objetivo primário entender e conhecer o cliente de tal maneira que qualquer serviço ou produto seja adequado ao cliente e se venda sozinho. "O marketing envolve a identificação e a satisfação das necessidades humanas e sociais" (KOTLER; KELLER, 2006, p.4). Esses autores sustentam que, em uma situação ideal, o marketing deveria resultar em um cliente disposto a comprar, portanto, a única coisa necessária para a realização da compra seria tornar o produto ou o serviço disponível.

No marketing, o potencial para troca existe quando cada uma das partes tem algo de valor potencial para oferecer à outra. Ou seja, quando ambas as partes podem se comunicar e entregar bens e serviços desejados, uma troca pode ocorrer. O marketing é, portanto, inspirado no princípio do certo, onde tenta-se "oferecer os bens e serviços certos para as pessoas certas, no lugar certo e ao preço certo". (MCDANIEL; GATES, 2003, p.6). - há uma complexidade de fatores e informações que a pesquisa em marketing torna possível descobrir.

Para Kotler (2000) "marketing é um processo por meio do qual pessoas e grupos obtêm aquilo de que necessitam e desejam através da criação, oferta e livre negociação de produtos e serviços de valor entre empresa e mercado consumidor".

De acordo com o Ferreira (2000) o termo marketing significa "conjunto de estratégias e ações relativas a desenvolvimento, apreçamento, distribuição e promoção de produtos e serviços e que visa à adequação mercadológica destes".

Marketing foi definido por Neves e Castro (2009), como um processo social e de gestão pelo qual indivíduos e grupos obtêm o que necessitam e querem através da criação, oferta e troca de produtos e valores com outros. 


\subsection{Agronegócio}

O Agronegócio - ou o Agro, como passou a ser chamado - é a denominação dada à cadeia produtiva relacionada à agricultura e à pecuária, incluindo todas as culturas agrícolas e espécies animais de produção, como o gado de corte e de leite, suínos, aves e até peixes. Tudo o que se origina no campo é considerado Agro, por isso esse setor é imenso, extremamente importante para a economia do Brasil e representa cerca de $23 \%$ do nosso PIB. Tudo tem um pouco do Agro: os alimentos, as roupas, os livros, os móveis e até o biocombustível. A cadeia produtiva do setor é bem extensa e congrega diversos segmentos de negócios, categorias de produtos e áreas profissionais, que estão presente antes, dentro e depois da porteira das propriedades rurais, chegando até o consumidor urbano. Há cerca de 50 anos o Brasil se encontrava em uma posição vulnerável de importador de alimentos para atender ao déficit existente na demanda interna. O índice do agronegócio de 2014/2015 aponta um crescimento de 15\% em recursos investidos, esses índices apontam o crescimento na produção agrícola, ajudando na continuidade de capitalização, modernização e também na inovação na área do agronegócio.

Para ZYLBERSZTAJN (2000), o agronegócio engloba todo o ciclo de produção rural, desde a compra de insumos e máquinas, o plantio a colheita, o transporte, o armazenamento, até a venda da produção e o consumo final.

A divisão de atividades é outra relação sobre o agronegócio, como conduzir desde a administração, a produção, a distribuição de seus produtos para chegar ao seu consumidor e ao preço final de venda. Essas relações são a intermediação sobre a produtividade agrícola do sistema do agronegócio. (ARAUJO, 1990).

O conceito de Giddens (2008) sobre o agronegócio já é antigo. No ano de 1957, dois pesquisadores americanos, Davis e Goldberg, o definem como a soma total das operações de produção e distribuição de suprimentos, das operações de produção nas unidades agrícolas, do armazenamento, do processamento e da distribuição dos produtos agrícolas e dos itens produzidos a partir deles. 
Em Mendes e Junior (2007 apud FLORES, 2016, p.5), temos:

\begin{abstract}
a sociedade Brasileira descobriu, há poucos anos, a importância do agronegócio. Antes, agropecuária e as indústrias de transformação de suas matérias-primas eram relegadas a um plano inferior. $O$ produtor rural, inclusive, era incompreendido e muitas vezes execrado como um pária do sistema econômico. Foi preciso uma crise internacional, que praticamente quebrou o Brasil no final do século passado, para demonstrar a relevância do setor como o principal formador de divisas e o grande motor da sociedade do interior do país, onde a renda que gera é fundamental para o sustento de todas as outras atividades econômicas.
\end{abstract}

Philip Kotler (2000), um dos principais pensadores do marketing, expõe sobre as várias atividades empresariais, atividades essas que podem influenciar nas decisões de compra dos consumidores, com isso o professor Jerome McCarthy, na década de 60, propôs os famosos 4 P's do marketing: Produto, Preço, Praça e Promoção. Esta estrutura possibilita aos profissionais decisões sobre o produto e suas características, decisões sobre o preço, sobre como distribuir os produtos e como promovê-los ao mercado consumidor.

\title{
2.30 agronegócio no Brasil
}

O agronegócio brasileiro movimenta cerca de 40\% PIB (Produto Interno Bruto) brasileiro e tem excelentes condições de ampliar ainda mais a sua contribuição para o desenvolvimento econômico e social do Brasil com capacidade para crescer muito acima da média de outros países pois tem se mostrado uma atividade próspera e rentável. É hoje uma das principais ferramentas da economia brasileira. Atualmente, o complexo agroindustrial tem sido o único setor da economia a apresentar saldo positivo na balança comercial. Os muitos benefícios econômicos e também sociais tem sido bem relevantes e estão promovendo a integração da sociedade brasileira em programas que visam promover o crescimento e o desenvolvimento do setor. De acordo com Neves et al (2000a), o agribusiness é um setor que interioriza o desenvolvimento, distribui renda, gera emprego e traz inúmeros outros benefícios sociais (cada milhão investido, segundo o BNDES, gera em torno de 140 empregos). 
A década de 1990, mesmo com perdas econômicas governamentais, o agronegócio brasileiro confirmou sua competitividade. O aumento substancial da produção tornou a crise histórica do abastecimento de alimentos uma coisa do passado. Como resultado, a tecnologia continua avançando e modernizando o campo, e até mesmo o uso de fertilizantes químicos dobrou na última década. $\mathrm{O}$ mercado global do agronegócio brasileiro está se consolidando como o maior gerador de saldo comercial para o Brasil, pela sua competitividade em custos e a qualidade de produtos, apesar do protecionismo internacional. (Congresso Brasileiro de Agribusiness).

O desempenho atual dos principais setores do agronegócio brasileiro costuma ser positivo, pelo menos para a maioria das atividades agrícolas. No caso de lucros escassos, aqueles que cooperam com os gestores profissionais e procuram manter uma relação positiva entre receita e custos "sobrevivem" no agronegócio. A estimativa de safra divulgada pela Conab em novembro mostrou variações no verão. $O$ foco está justamente no carro-chefe da agricultura do país, a soja, que tem estimativa de crescimento de $1,4 \%$. Na pecuária, as características de um longo ciclo da pecuária indicam que a oferta da carne continua limitada, o que deve manter ou ampliar o mercado interno em substituição à proteína, principalmente de frango. No geral, essas indústrias devem aumentar a produção e as vendas da indústria de carnes.

O grande salto do agronegócio brasileiro nos últimos anos refere-se ao mercado externo. A relação com o mercado externo sempre dependeu de determinados produtos (como açúcar, borracha, café, cacau e fumo). Países com ciclos longos e isolados do mundo começaram a diversificar suas operações e passaram a se envolver em uma ampla gama de produtos de comércio internacional, quase todos os produtos com forte competitividade.

Devido à crise econômica, vários setores do Brasil estão economicamente debilitados. Nossa economia realmente perdeu a coordenação, mas especialmente para uma economia que depende fortemente da agricultura, o Brasil teria sentido muito se não fosse pelo seu agronegócio. É preciso lembrar que, o "campo foi e continua sendo um grande mercado para tecnologias, produtos e serviços." 


\subsection{Marketing para o agronegócio no século XXI}

A evolução do setor agropecuário brasileiro tem sido um processo revolucionário e dinâmico, que a maioria da população não chega a ter ideia do seu alcance. Por se apresentar como uma verdadeira conquista atualmente, cabe priorizar a divulgação do setor e elaborar um plano de comunicação que mostre quão competitiva e sustentável é a agropecuária brasileira, e utilizando no marketing os recursos necessários para a evolução dos conceitos de gestão estratégia para o agronegócio.

Os desafios do agronegócio no Brasil para se manter no mercado do século XXI são muitos, seus produtos derivados do campo precisam chegar aos consumidores com identidade forte e o marketing no agronegócio é desenvolvido com esse intuito, o de ampliar as estratégicas dos envolvidos na agroindústria, por meio de técnicas de sucesso no marketing cujos esforços são sempre concentrados no consumidor final. Participando mais sobre as inovações de conceitos, necessidades, desejos e demandas, e seu mercado-alvo.

Espera-se uma expansão sem precedentes do mercado agrícola mundial, com destaque para além das carnes (bovina, suína e avícola), os lácteos também, que deverão dobrar as suas exportações até 2015, seguidos pela soja, arroz e açúcar. As políticas agrícolas que demonstram serem mais importantes para o futuro do setor no Brasil são reduzir a volatilidade cambial, abrir mercados e investir pesadamente em infraestrutura, defesa agropecuária e biotecnologia.

Entretanto, o sistema agronegócio, vigoroso, num de seus segmentos mais estratégicos que agrega os produtores rurais, em nível de campo, demanda cada vez mais e sempre as inovações tecnológicas, pesquisas de ponta, novas habilidades humanas, máquinas e equipamentos agrícolas de última geração.

São inúmeras as ferramentas de marketing utilizadas no agronegócio, entretanto, podemos destacar que o marketing digital é o principal aliado das 
empresas na atualidade. Segundo uma pesquisa realizada pela Associação Brasileira de Marketing Rural e Agronegócio (ABMRA), desde 2013 houve um aumento de $48 \%$ no uso de dispositivos moveis por agricultores rurais e em 2017 o número subiu para 61\%, esses em sua maioria possuem redes sócias, possibilitando que as empresas que utilizam essa ferramenta para divulgação dos seus serviços, produtos e outros conteúdos relevantes obtenham um diferencial que pode aumentar significativamente seus rendimentos, além da possibilidade de uma melhor comunicação com o consumidor, pois possibilita uma facilidade de interação e engajamento. Além das redes sociais o mercado digital possibilita a criação de sites, investimento em mídia paga e aplicativos para celular que é a nova tendência. Atualmente pode-se encontrar aplicativos que auxiliam na nutrição animal, monitoramento de maquinas, georreferenciamento, catálogo de produtos, identificação de plantas, dosagem de produtos, entre outros, enfim, otimizando o setor. Entretanto, são oferecidas diversas oportunidades no agronegócio através do marketing digital, melhorando os resultados de vendas e possibilitando a consolidação das empresas.

\section{Considerações Finais}

Considerando o que foi exposto neste trabalho sobre marketing, agronegócio e estratégia percebe-se que o marketing é uma ferramenta que tem ajudado muito em todo o processo de venda e troca de produtos ou serviços e o como as estratégias de marketing são fundamentais para agregar mais valor ainda a esse processo, mas que ainda existe a necessidade de um pouco mais de avanço para maior valorização do setor, o levantamento bibliográfico apresentado é enfático quanto a isso.

O agronegócio é fundamental, pois vem agregando valor a seus produtos e marca, as ações são pertinentes ao mercado, preço, produto, concorrente, logística, vendas, propaganda, público alvo e é perceptível que o agronegócio no Brasil tem alavancado a economia brasileira e sustentado o país no que se refere ao PIB. Com tais considerações observa-se a urgência em focar mais no sistema 
produtivo agribusiness já que o Marketing pode desenvolver ações concretas para o empreendimento possuir maior valor agregado.

Com toda uma característica típica que o nosso país possui para esse tipo de atividade e com propostas de ações entende-se que todo o sistema e todos os produtos/serviços serão potencializados com grande valor agregado, tornando a lucratividade expressiva gerando riquezas inerentes a área humana, tecnológica, produtiva e segmentos relacionados fazendo esse setor crescer potencialmente aumentando sua eficácia e o marketing é a ferramenta principal para tal crescimento.

\section{Referências}

ARAÚJO, Massilon. J. Fundamentos de agronegócio. São Paulo: Atlas, 2003.

CASTRO, Luciano Thomé; NEVES, Marcos Fava. Marketing e estratégia em agronegócios e alimentos. Editora Atlas S.A, São Paulo, 2009.

CONTENT, R. A importância do marketing no agronegócio para os produtores rurais. 2017. Disponível em: <https://marketingdeconteudo.com/marketing-noagronegocio/> Acesso em: 26 abril de 2021.

FERREIRA, Armando Leite. Marketing para pequenas empresas inovadoras. Rio de Janeiro: Expertbooks, 1995.

FLORES, Rafael Telch. A importância do marketing para o agronegócio brasileiro. (2016). Disponível em: <http://www.portaldoagronegocio.com.br> Acesso em 10 janeiro de 2021.

GERHARDT, Tatiana Engel; SILVEIRA, Denise Tolfo. Métodos de Pesquisa. Porto Alegre: Editora da UFRGS, 2009.

GIDDENS, Anthony. Confiança e Modernidade. São Paulo: Editora UNESP, 1991. 
JANSEN, Marcos Garcia. O marketing e o agronegócio Il. Disponível em: < http.//www.Agroline.com.br/artigos > acesso em 5 de março de 2021.

KOTLER, Philip; KELLER, Kevin L. Administração de marketing. 12. ed. São Paulo: Pearson Prentice Hall, 2006.

MCDANIEL, C.D.; GATES, R. Pesquisa de marketing. São Paulo: Pioneira Thomson Learning, 2003. 562 p.

MEDINA, G. Dinâmicas internacionais do agronegócio e implicações para a política agrícola brasileira. Revista de Estudos Sociais, v. 19, n. 38, p. 3-12, 2017.

MEGIDO, José Luiz Tejon. Marketing \& Agribusiness - 3aㅡ edição - Editora Atlas - São Paulo - 1998.

OLIVEIRA, J.A. O que significa agronegócio? 2010. Sociedade Espiritosense de Engenheiros Agrônomos. Disponível em:

<http://www.seea.org.br/artigojoseadilson2.php> Acesso em 15 fevereiro de 2021.

RUFINO, José L.S. Origens e conceitos do agronegócio. Informe Agropecuário, Belo horizonte: Epamig, v.20, no 199, Jul./Ago. 1999.

SILVA, C. Marketing no Agronegócio. 2015. Disponível em: <https://cepein.femanet.com.br/BDigital/arqTccs/1211390746.pdf> Acesso em 26 abril 2021.

SOARES, Mario Luiz. Marketing. Curso de especialização MBA com ênfase em finanças. Disciplina de Marketing. Cascavel, 1998

TERRA. Tendências do marketing no agronegócio do futuro. 2016. Disponível em: <https://www.terra.com.br/noticias/climatempo/9-tendencias-do-marketing-noagronegocio-do-futuro,dec4604ca879bfe7aaa334648185b2e9zigvzfml.html> Acesso em: 06 março de 2021. 
Revista Multidisciplinar do Nordeste Mineiro, v.2 $2021 / 02$

ISSN 2178-6925

TERRA, Thiago. Agronegócio muda com estratégias de marketing. (2010).

Disponível em:<http://www.exame.abril.com.br> Acesso em 10 fevereiro de 2021.

ZYLBERSZTAJN, D. Conceitos gerais, evolução e apresentação do sistema agroindustrial. In. Gestão dos negócios agroalimentares: Indústria de alimentos, indústria de insumo, produção agropecuária. Décio Zylbersztajn \& Marcos Fava Neto (org.). São Paulo: Pioneira, 2000. 